Revista Eletrônica do Mestrado em Educação Ambienta1

\title{
Políticas de Currículo da Educação Ambiental no contexto de uma escola pública de Pernambuco ${ }^{1}$
}

Everaldo Nunes de Farias Filho ${ }^{2}$

Universidade Federal Rural de Pernambuco - UFRPE https://orcid.org/0000-0003-1414-3291

Carmen Roselaine de Oliveira Farias ${ }^{3}$ Universidade Federal Rural de Pernambuco - UFRPE https://orcid.org/0000-0001-8823-7771

Resumo: Nesta pesquisa buscamos compreender de que modo professores recontextualizam duas políticas educacionais nacionais de Educação Ambiental (EA) - Política Nacional de Educação Ambiental (PNEA) e as Diretrizes Curriculares Nacionais para a Educação Ambiental (DCNEA) e deliberam sobre a construção do currículo escolar que insere a EA em uma escola pública de Pernambuco. Utilizando o referencial teórico-metodológico do ciclo de produção de políticas curriculares segundo Stephen Ball e seus colaboradores e intérpretes brasileiros, procuramos responder aos objetivos dessa pesquisa acerca dos principais significados de EA, concepções de currículo e propostas de ensino acionadas pelos professores no processo de construção de um plano de ação em EA.

Palavras-chave: Educação Ambiental. Políticas Educacionais. Currículo.

\section{Políticas de Currículo de la Educación Ambiental en el contexto de una escuela pública de Pernambuco}

Resumen: En esta investigación buscamos comprender de qué modo los profesores recontextualizan dos políticas educativas nacionales de Educación Ambiental (EA) - Política Nacional de Educación Ambiental (PNEA) y las Directrices Curriculares Nacionales para la Educación Ambiental (DCNEA) - y deliberan sobre la construcción del currículo escolar En una escuela pública de Pernambuco. Utilizando el referencial teórico-metodológico del ciclo de

\footnotetext{
${ }^{1}$ Este artigo é parte da pesquisa de mestrado do primeiro autor e apresenta uma síntese dos principais resultados alcançados, os quais foram apresentados parcialmente no VIII EPEA - Encontro Pesquisa em Educação Ambiental.

${ }^{2}$ Doutor em Ensino das Ciências e Matemática pela UFRPE, Professor do Colégio Agrícola Dom Agostinho Ikas da UFRPE, Pernambuco, Brasil. E-mail: everaldo_nff@hotmail.com

${ }^{3}$ Doutora em Educação pela UFSCar, Professora do Departamento de Biologia-UFRPE, Coordenadora do Programa de Pós Graduação em Ensino das Ciências, Pernambuco, Brasil. E-mail: crofarias@gmail.com
} 
producción de políticas curriculares según Stephen Ball y sus colaboradores e intérpretes brasileños, procuramos responder a los objetivos de esta investigación acerca de los principales significados de EA, concepciones de currículo y propuestas de enseñanza accionadas por los profesores en el proceso de construcción de un plan de acción en EA.

Palabras clave: Educación Ambiental. Políticas Educativas. Plan de Estudios.

\title{
Environmental Education Curriculum Policies in the context of a public school in Pernambuco
}

\begin{abstract}
In this research we understand that teachers reinterpret and recontextualize texts of two national Environmental Education educational policies (EA) - National Environmental Education Policy (PNEA) and National Guidelines for Environmental Education (DCNEA) - and deliberate on the construction of the curriculum of EA in a public school in Pernambuco. Using the theoretical framework of the curriculum policy production cycle according to Stephen Ball and his colleagues and Brazilian performers, seek to answer the objectives of this research on the main meanings of EA, curriculum conceptions and epistemological and methodological assumptions of education triggered by the teachers in the process building a plan of action in EA.
\end{abstract}

Key words: Environmental Education. Educational Policy. Curriculum.

\section{Introdução}

A questão ambiental, como uma problemática global, tem mobilizado as sociedades no sentido do desenvolvimento de práticas sociais orientadas para a sustentabilidade socioambiental. No que se refere à esfera educacional, existe um consenso sobre a importância da inserção das temáticas ambientais em todos os níveis de ensino, entendimento já regulamentado em políticas educacionais brasileiras.

As discussões acerca da questão ambiental em âmbito nacional e internacional serviram de base para a criação no Brasil, a partir dos anos 90, de políticas nacionais de educação ambiental, cujos textos expressam sua relevância e premência em diversos espaços sociais, bem como em todas as modalidades e níveis de ensino.

Entre as principais políticas destaca-se a Lei Federal 9.795/99, que institui a Política Nacional de Educação Ambiental (PNEA), a qual já conta com mais de vinte anos e a promulgação da Resolução n 02 de 15 de junho de 2012 e do Parecer CNE/CP n ${ }^{\circ}$ 14/2012 que apresentam as Diretrizes Curriculares Nacionais de Educação Ambiental (DCNEA). Essas últimas têm um significado particular para os sistemas de ensino e suas instituições de Educação Básica e de Educação Superior, por se constituir um instrumento voltado a oferecer entendimentos "comuns" para a EA no contexto nacional".

\footnotetext{
${ }^{4}$ Sobre o propósito de definir padrões comuns em nível federal, remete-se às discussões sobre a produção de um currículo nacional. Segundo Lopes (2006), o que haveria de comum ou de universal em uma política curricular nacional é sempre uma particularidade que foi universalizada. Nessa acepção, o currículo nacional constitui um horizonte imaginado por sujeitos coletivos e individuais que articulam seus interesses e suas redes de poder em torno de um mesmo
}

Rev. Eletrônica Mestr. Educ. Ambient. Rio Grande, v. 37, n. 3, p. 263-282, mai./ago. 2020.

E-ISSN 1517-1256 
No entanto, um aparente obstáculo para a concretização das orientações expostas em tais políticas costuma ser o desconhecimento dos textos pelos profissionais da educação, sendo essa uma situação trivial em contextos escolares. Desse problema, surgiu para nós a seguinte indagação de pesquisa: de que modo professores interpretam tais políticas educacionais e que caminhos tomam para deliberar sobre a construção do currículo escolar de EA?

Para uma aproximação ao entendimento dessa questão, foi proposta uma ação formativa junto a um grupo de professores da Educação Básica, com intuito de provocar discussões a respeito dos textos da PNEA e das DCNEA. Assim, os objetivos desta pesquisa são: compreender de que forma os professores recontextualizam as políticas de EA na construção do currículo escolar e analisar as principais ideias, conteúdos e metodologias acionadas por eles em um contexto de produção coletiva de um plano de ensino. Vale salientar que nosso objetivo não foi o de legitimar tais políticas junto aos professores, mas o de compreender como esses atores educacionais as utilizam (quando as utilizam) em suas práticas escolares.

\section{Quadro teórico: políticas curriculares nacionais de educação ambiental}

A partir de discussões que inseriram a temática ambiental em diferentes contextos sociais, entre os quais está o educacional, a EA passou a permear os espaços escolares de modo a fazer parte do processo de construção das políticas curriculares desses ambientes. Nesta pesquisa, entendemos que as políticas curriculares visam à construção do conhecimento escolar e são compostas por propostas e práticas curriculares (LOPES, 2004; MACEDO, 2006).

De acordo com a policy cycle approach ou abordagem do ciclo de políticas, formulada por Bowe, Ball e Gold (1992), a produção das políticas curriculares - dentre elas, as de EA - passam por três contextos políticos primários, cada um deles com diversas arenas de ação, públicas e privadas (LOPES, 2004; MAINARDES, 2006). Esses contextos situam-se em um ciclo contínuo de políticas e podem ser genericamente definidos como: a) contexto de influência, onde normalmente as definições políticas são iniciadas e os

projeto. Contudo, como política cultural, o currículo é fruto de um embate por sentidos e significados que ultrapassa não apenas o espaço físico da sala de aula, mas também o território imaginado do que se supõe que deve ser uma aula. Recontextualizações por hibridismos geram produções de múltiplos sentidos e significados que desestabilizam a ideia de uma homogeneidade cultural ou um padrão único a ser incorporado.

Rev. Eletrônica Mestr. Educ. Ambient. Rio Grande, v. 37, n. 3, p. 263-282, mai./ago. 2020.

E-ISSN 1517-1256 
discursos políticos são construídos; b) contexto de produção dos textos das definições políticas, o poder central propriamente dito, que mantém uma associação estreita com o primeiro contexto; e c) contexto da prática, onde as definiçõos curriculares estão sujeitas a serem recriadas e reinterpretadas pelos educadores dentro da escola.

A esta abordagem se junta à noção de recontextualização, a qual tem se evidenciado produtiva para o entendimento das reinterpretações que sofrem os diferentes textos na sua circulação pelo meio educacional:

[...] são orientações de agências multilaterais que se modificam ao serem inseridas nos contextos dos Estados-nação; são orientações curriculares nacionais que são modificadas pela mediação de esferas governamentais intermediárias e das escolas; são políticas dirigidas pelo poder central de um país que influenciam políticas de outros países; são ainda os múltiplos textos de apoio ao trabalho de ensino que se modificam nos contextos disciplinares (LOPES, 2005, p. 53).

De acordo com Lopes (2005), no processo de recontextualização os textos das políticas curriculares nacionais são modificados pela mediação de esferas governamentais estaduais e municipais e pelas instituições de ensino. Nesse sentido, a autora explica que durante a circulação das políticas curriculares pelo corpo social da educação alguns trechos são destacados em detrimento de outros que, por sua vez, se articulam a outros fragmentos de textos gerando discursos ambientais híbridos.

Nesse sentido, os textos das políticas curriculares de EA são fruto de processos de recontextualização dos discursos de sustentabilidade das correntes político-ideológicas do campo da EA que acontecem em todos os contextos políticos primários apresentados por Ball. Dessa forma, o processo de recontextualização não se finaliza com a redação final do texto da política curricular de EA, mas tem continuidade durante o percurso da política pelo ambiente escolar. De acordo com Lopes (2005, p.56) os contextos políticos primários "formam um ciclo de políticas sempre sujeitos a processo de recontextualização". Tomando por base as ideias de Lopes (2005), ao chegar à escola, as políticas de EA são reinterpretadas pelos atores educacionais gerando discursos híbridos de sustentabilidade que orientam suas práticas educativas.

O foco dessa pesquisa está no contexto da prática, cenário em que professores e demais atores escolares continuam o processo de construção do currículo na escola por meio da recontextualização das políticas curriculares. Segundo Ball, Maguire e Braun (2016), os atores escolares participam do movimento de elaboração do currículo quando 
interpretam e reinterpretam situações, lêem textos, discutem e lutam para defender seus pontos de vista e modificam a maneira de colocar a política curricular em prática com diferentes interpretações. Mainardes (2006) afirma que, na abordagem do ciclo de políticas, os textos das políticas educacionais não chegam à escola apenas para serem executados, como prescrições para serem cumpridas de cima para baixo, mas estão sujeitos a reinterpretações dos profissionais que atuam nas instituições de ensino.

Para Ball e Bowe (1992), o contexto da prática abrange as práticas de dentro e de fora da sala de aula, e no qual as políticas educacionais curriculares são reinterpretadas e recriadas por professores e demais agentes educacionais para relacionar os textos políticos às suas práticas cotidianas. Corroborando com Marcondes, Freund e Leite (2017), consideramos que os docentes e outros profissionais escolares são protagonistas das políticas e atuam como podem dentro dos limites que lhes são determinados. Contudo, os professores não interpretam os textos políticos de forma ingênua. Cada docente está imbuído de suas próprias histórias, concepções, valores e experiências que orientam suas análises dos textos políticos. Dessa forma, algumas propostas podem ser aceitas, ignoradas, rejeitadas, mal interpretadas ou reproduzidas pelos docentes durante o processo de construção do currículo (FARIAS FILHO, 2014). É nesse sentido que Ball e seus colaboradores apresentaram a Theory of Policy Enactment (Teoria da Atuação Política) e desenvolvem o uso do termo enactment aprofundando a ideia de que as políticas não são apenas implementadas, mas recriadas e reinterpretadas pelos atores educacionais (MAINARDES, 2018).

Essa perspectiva sugere que, inclusive com uma legislação bem detalhada, a política educacional é sempre gerada, reinterpretada e implementada dentro e ao redor de um sistema, produzindo consequências tanto para o campo da educação como para o ambiente social que a cerca. Como resultado disso, a lei e os textos que a acompanham expressam tanto conjuntos de intenções políticas e um recurso político para a continuidade dos debates nacionais, quanto um recurso micropolítico para que os professores, as autoridades e os pais interpretem e apliquem a política em seus contextos sociais particulares (FARIAS, 2008).

Além de se configurar como texto sujeito a reinterpretações e leituras diversas, a política curricular também se apresenta como discurso. Segundo Lopes (2006) no campo educacional circulam discursos que são base da produção de sentidos e significados das políticas curriculares. Como discurso, a política constitui "práticas que formam os objetos 
dos quais falam e que se associam ao que pode ser dito, a quem pode dizer, quando e com que autoridade" (LOPES, 2006, p. 38). Para Foucault (2006), o discurso está dentro das relações de saber e poder. Nas relações de saber quando produz o conhecimento e cria os objetos dos quais fala e nas relações de poder na medida em que se alia a ideia de verdade e apresenta a capacidade de controlar pessoas. Nesse sentido, o currículo como discurso gera disputas entre os diferentes significados atribuídos pelos sujeitos, produzindo e influenciando as práticas escolares.

Nesse sentido, os "efeitos das políticas como textos e como discursos são contextuais e estabelecem constrangimentos para as políticas" (LOPES, 2006, p.38). Sendo múltiplos os produtores de textos e discursos - governos, meio acadêmico, práticas escolares, mercado editorial, grupos sociais os mais diversos e suas interpenetrações -, com poderes assimétricos, são múltiplos também os sentidos e significados em disputa.

\section{$O$ contexto da pesquisa e o caminho percorrido}

A presente pesquisa foi desenvolvida dentro de uma abordagem qualitativa (GRAY, 2012), por meio de contato intenso dentro de um campo ou contexto da vida real e seu principal foco é entender as formas como as pessoas agem e explicam suas ações.

O campo da pesquisa foi uma escola municipal de natureza pública, situada no município de Carpina localizado na zona da mata norte do estado de Pernambuco. Com cerca de sessenta anos de existência, a escola localiza-se no centro do município, o que justifica a presença de alunos de diferentes bairros da cidade, oferecendo ensino formal em nível Fundamental a alunos de diversas comunidades do município. Funciona nos três turnos, sendo que os períodos da manhã e tarde são dedicados a alunos matriculados nas séries regulares do Ensino Fundamental do $6^{\circ}$ ao $9^{\circ}$ ano e o período da noite atende a alunos na modalidade da Educação de Jovens e Adultos também para as etapas do Ensino Fundamental.

O público-alvo da pesquisa foi um grupo de doze professores de diferentes disciplinas que lecionam na escola no período da manhã nas turmas de $6^{\circ}$ ao $9^{\circ}$ ano. A opção pelo turno da manhã se deu pelo fato de ser o horário em que houve maior adesão dos participantes da pesquisa. O grupo de professores foi constituído por docentes das áreas de Língua Portuguesa, Matemática, Biologia, Química, História, Geografia, Artes, Língua Inglesa e Ensino Religioso.

Rev. Eletrônica Mestr. Educ. Ambient. Rio Grande, v. 37, n. 3, p. 263-282, mai./ago. 2020. E-ISSN 1517-1256 
A escola, em que se realizou este estudo, apresenta documentos curriculares escolares como o Projeto Político Pedagógico (PPP), Regimento Escolar e Plano de Ensino dos professores que norteiam a prática pedagógica da comunidade escolar. Entretanto, os dois primeiros documentos não fazem nenhuma menção acerca da inserção da EA nas ações da escola, sendo que apenas alguns planos de ensino citam conteúdos relacionados à EA. Dessa forma, as práticas de EA limitam-se a ações pontuais como conteúdos de algumas disciplinas, feiras de ciências e projetos multidisciplinares temporários.

Um dos desafios deste estudo foi encontrar a forma adequada de coleta de dados para responder a algumas das questões de pesquisa. Como o objetivo da pesquisa é compreender de que modo os professores reinterpretam e recontextualizam os textos das políticas educacionais e deliberam sobre a construção do currículo escolar que insere a EA, surgiu a necessidade de criar espaços para que os professores tivessem a oportunidade de discutir e refletir sobre o tema pesquisado.

Assim, os professores foram reunidos e estimulados a refletir e debater sobre as questões de pesquisa de forma dinâmica. Essa inquietação surgiu das seguintes dúvidas: como poderíamos pedir aos professores que refletissem sobre as políticas educacionais de EA se não sabíamos até que ponto eles conheciam o conteúdo dos textos oficiais? De que modo indagá-los sobre a inserção da EA em suas práticas cotidianas sem conhecer suas concepções sobre a EA? Como entender o processo da ambientalização curricular nesta escola sem inteirar-se da visão de currículo apresentada pelos docentes? Qual a melhor maneira de estimular os professores a participar assiduamente e ativamente das discussões?

\section{O Minicurso}

A partir dessas indagações foi criado o minicurso intitulado A Educação Ambiental e a Interdisciplinaridade no Ensino Fundamental constituído de seis encontros, totalizando trinta horas e que se caracterizou como cenário para a realização das discussões entre os docentes. Os encontros do minicurso tiveram duração de cinco horas cada e foram gravados em áudio e vídeo e em seguida transcritos. Por meio da técnica do grupo focal, o grupo de professores realizou debates sobre a produção do currículo em EA. A análise dos dados se deu a partir dos debates realizados pelos professores que nos deram base para responder à questão pesquisada.

O primeiro encontro teve início com a apresentação da estrutura, dos objetivos e da metodologia utilizada no minicurso aos participantes. Também foi esclarecido aos 
professores que o minicurso fazia parte da metodologia do projeto de dissertação de mestrado do primeiro autor e seria utilizado como cenário para a coleta de dados referentes à pesquisa.

Após a apresentação da proposta, algumas questões de pesquisa foram apresentadas por meio de conversas informais, o que oportunizou uma série de discussões em relação aos temas abordados. Os professores foram orientados a responder às indagações de forma ordenada e a concordarem ou discordarem das opiniões apontadas pelos colegas sempre que achassem necessário.

O debate foi permeado por questões que abordaram temas como: a) concepções de EA dos professores, b) formas de inserção da EA em contextos escolares, c) construção de conhecimento de EA por alunos e professores, d) origem das fontes de conhecimentos ambientais dos professores, e) dificuldades e facilidades para a inserção da EA em contextos escolares e, f) metodologias utilizadas para inserir a EA nas práticas escolares cotidianas. O objetivo desse primeiro encontro foi verificar as visões de EA dos professores que orientam suas práticas ambientais dentro da escola, visando ter um primeiro contato com os pressupostos epistemológicos e metodológicos relacionados aos conhecimentos ambientais que mobilizam a produção do currículo que insere a EA.

O segundo encontro do minicurso teve como objetivo principal estimular os professores a ler e discutir sobre o texto da Lei Federal n 9.795/99 que institui a Política Nacional de Educação Ambiental (PNEA). Com o intuito de tornar a leitura do texto da lei mais dinâmica, utilizamos três casos fictícios em que cada um referia-se a uma parte do texto da PNEA e abordavam temas controversos em EA e que são abordados pela lei. Os casos, de autoria do primeiro autor, narravam reuniões com professores, direção e equipe pedagógica de três escolas diferentes sobre a inserção da EA em contextos escolares.

Os professores foram divididos em três equipes, onde cada grupo ficou responsável por analisar a reunião de uma escola fictícia. Num primeiro momento, a análise de cada caso foi feita sem a interferência do texto da PNEA. Em seguida, cada equipe socializou suas percepções sobre os casos analisados. Após esse momento de discussão, os professores foram estimulados a analisar novamente as falas das personagens de cada caso à luz do texto da PNEA e em seguida, comentá-los a partir de suas percepções. Após a análise, cada equipe de professores apresentou suas interpretações dos casos utilizando o texto da Lei para fundamentar seus argumentos. Dessa forma, além de promover uma leitura dinâmica do texto da PNEA, esse encontro serviu para os professores expressarem 
suas interpretações da lei, concordando ou discordando das propostas dessa política educacional.

O terceiro encontro do minicurso teve como meta a leitura do texto da Resolução $n^{\circ}$ 02/2012 do CNE que estabelece as Diretrizes Curriculares Nacionais para a Educação Ambiental (DCNEA). Como os professores já estavam familiarizados com a estrutura do texto da PNEA (artigos, incisos, parágrafos), optamos em dividir o texto das DCNEA em quatro partes (Título I, II, III e IV) de forma que cada uma fosse discutida por uma equipe diferente de professores.

Os professores de cada equipe foram orientados a ler e discutir sobre suas partes e prepararem uma apresentação com slides para socializar suas interpretações. Em seguida, cada grupo de professores apresentou seus comentários sobre as DCNEA proporcionando um debate entre os grupos e a troca de informações sobre as partes do texto das diretrizes.

Durante os três primeiros encontros, os professores decidiram que a EA deveria ser inserida no currículo escolar na forma de projetos contínuos e interdisciplinares. Em meio a esses debates, apareceram sugestões que apontavam para a escolha de problemas socioambientais enfrentados pela escola que seriam agrupados em um tema central para orientar a construção de um plano de ação em EA a ser implementado na escola durante o ano letivo.

Diante disso, o quarto encontro do minicurso foi realizado com o objetivo de criar um ambiente de discussões entre os professores visando como resultado final a escolha de um tema gerador. Contudo, houve a necessidade de que temas como currículo e interdisciplinaridade fossem objetos de discussão entre os professores, já que os docentes optaram por inserir a EA no currículo da escola por meio de projetos interdisciplinares.

Neste sentido, iniciamos o quarto encontro com uma rodada de debates para que os professores pudessem exteriorizar suas concepções sobre currículo. Em seguida, promovemos uma discussão sobre diferentes visões de currículo trazidas pela literatura por meio dos estudos de Lopes (2004; 2006), Macedo (2006), Lopes e Macedo (2011) e sobre a teoria da construção das políticas curriculares baseados nos estudos de Bowe, Ball e Gold (1992). A justificativa para a realização dessas discussões veio do fato de considerarmos importante que os professores tivessem acesso a visões diferentes de currículo para que pudessem ampliar seu campo de conhecimento sobre esse tema.

Dando continuidade ao quarto encontro, promovemos outro momento de debates, dessa vez com o tema interdisciplinaridade. Esse tema foi abordado com a utilização de 
figuras que representam a ideia de disciplinaridade, multidisciplinaridade e interdisciplinaridade e com o uso de um vídeo sobre interdisciplinaridade de Edgar Morin (disponível em www.youtube.com/watch?v=klZ3ZuiCx4A). Isso serviu de base para que os professores deliberassem sobre a escolha de um tema interdisciplinar central e expressassem suas sugestões sobre como seria construído o plano de ação a ser aplicado na escola.

Realizadas as reflexões sobre currículo e interdisciplinaridade, os professores foram orientados a escolher temáticas que englobassem problemas socioambientais presentes na escola pesquisada. Cada professor anotou suas escolhas em tarjetas de papel e foram orientados a categorizá-las por convergência de temas. Feita a categorização, abrimos um espaço para que cada professor justificasse suas opções e se posicionassem sobre as escolhas dos outros docentes. $\mathrm{O}$ resultado desse momento foi o surgimento de uma grande quantidade de temas diferentes. Dessa forma, houve a necessidade de criar critérios para a seleção desses temas. Um dos critérios estabelecido pelos professores era que o tema deveria ser interdisciplinar. A partir desse critério, os professores foram agrupando suas sugestões de acordo com as relações que eles identificavam entre os temas propostos.

Esse debate resultou na escolha da temática consumismo e do tema central A práxis da Educação Ambiental na busca de soluções para minimizar o consumismo, que engloba as categorias de problemas elencadas pelos professores como lixo, depredação do ambiente escolar, relações interpessoais, higiene e saúde.

O consumismo já havia sido apontado por alguns professores nos encontros anteriores como possível temática a ser trabalhada na escola em projetos de EA. Dessa forma, consideramos pertinente a ampliação da discussão sobre o consumismo entre os professores. Decidimos então mostrar o vídeo The Story of Stuff (A História das Coisas), de Annie Leonard (2011), no sentido de proporcionar aos professores um material que tratasse dessa temática. Esse vídeo serviu como objeto de análise para os docentes que debateram sobre a temática e relacionaram-na com os problemas socioambientais enfrentados pela escola.

Com a escolha do tema central, o quinto encontro do minicurso serviu como espaço para a aplicação de uma oficina que teve como meta a criação de um plano de ação interdisciplinar em EA com o tema escolhido para ser aplicado no ano seguinte por toda a escola. Vale salientar que a construção desse documento curricular escolar já tinha sido sugerida por alguns professores desde o primeiro encontro do minicurso. 
Com o objetivo de dar continuidade à discussão sobre o consumismo, optamos por utilizar dois materiais para retomar esse debate: a) um vídeo retirado da internet chamado E seu celular velho? b) um texto de Layrargues (2011) intitulado O cinismo da reciclagem: o significado ideológico da reciclagem das latas de alumínio e suas implicações para a educação ambiental. Esses materiais serviram de base para promovermos uma discussão a respeito de diferentes concepções de EA que circulam nos discursos de educadores ambientais no país.

Após esses debates, estimulamos os professores a estabelecerem critérios que nortearam a construção do plano de ação em EA. Uma perspectiva interdisciplinar e que abordasse problemas socioambientais enfrentados pela escola foram os critérios elencados pelos professores para a orientação da construção do Plano de Ação. No sentido de oferecer mais opções de critérios para guiar a construção do projeto, sugerimos aos professores a leitura do texto de Tomazello e Ferreira (2001), intitulado Educação Ambiental: que critérios adotar para avaliar a adequação pedagógica de seus projetos? $\mathrm{O}$ qual traz sugestões de critérios para avaliar projetos de EA.

O debate sobre esses critérios serviu de base para que os professores começassem a construir a justificativa do plano de ação. Em seguida, estimulamos os docentes a definirem, em conjunto, os conteúdos, objetivos, atividades que posteriormente iriam compor o plano de ação. A criação desse documento curricular da escola serviu para que pudéssemos colher dados para compreender como os professores deliberam e recontextualizam as políticas educacionais de EA na construção do currículo.

O sexto e último encontro do minicurso deu continuidade à elaboração do plano de ação. Nesse encontro, estimulamos os professores a revisarem o tema, a questão de pesquisa, a justificativa, os objetivos, as atividades propostas no plano de ação criado no encontro anterior, questionando-os se o projeto estava dentro de uma perspectiva interdisciplinar.

Revisado o plano de ação, conduzimos as discussões de forma que os professores fossem debatendo e construindo a metodologia e o cronograma bem como os critérios de avaliação do projeto e da aprendizagem dos alunos. Ao final, os professores decidiram que o projeto deveria produzir, de forma interdisciplinar, um jornal informativo que circularia na própria escola e uma página na rede social Facebook para socialização das atividades propostas e dos resultados alcançados pelo projeto. 
Concluído o plano de ação, iniciamos uma rodada de perguntas para promover reflexões dos professores sobre o processo de construção do projeto. Após esse momento, solicitamos aos professores que realizassem uma pequena avaliação de toda a trajetória do minicurso. Interessante destacar que todos os professores declararam estar bastante satisfeitos com o minicurso, afirmando que as discussões realizadas contribuíram para sua formação.

A participação do primeiro autor no minicurso foi de articulador das discussões estabelecidas no grupo, ao mesmo tempo em que coletava dados para esta pesquisa. $\mathrm{O}$ minicurso se configurou como motivação para que os professores participassem dos encontros com a meta de trocar experiências e ampliar os conhecimentos sobre a inserção da EA na escola e, ao mesmo tempo, se constituiu como campo de pesquisa para que pudéssemos coletar parte dos dados utilizados neste estudo. Neste sentido, o minicurso se configurou como um ambiente que oportunizou um espaço formativo e deliberativo para a construção do currículo que insere a EA a partir das reinterpretações da Política Nacional de Educação Ambiental (PNEA) e das Diretrizes Curriculares Nacionais para a Educação Ambiental (DCNEA).

\section{Educação ambiental no contexto da prática de uma escola de ensino fundamental: os professores em debate}

Com base nos resultados dessa pesquisa verificamos que os docentes discutem sobre EA se forem instigados. Percebemos que quando há a disponibilização de espaço, tempo e materiais para que essas discussões entre os docentes aconteçam, eles se envolvem, utilizando suas experiências e concepções para defender seus pontos de vista. Nessas discussões, alguns conceitos previstos nas políticas de EA são acolhidos durante o processo de produção do currículo enquanto outros são desconsiderados como veremos a seguir.

\section{Noção de currículo}

Antes de discutir sobre como os professores recontextualizam as políticas curriculares de EA dentro da escola houve a necessidade de compreender os significados que eles atribuem ao currículo. No que se refere à produção do currículo, os docentes pesquisados expressaram inicialmente uma concepção prescritiva de currículo, cuja 
elaboração seria de responsabilidade das instâncias governamentais cabendo aos professores apenas a função de executá-lo. Dessa forma, essa visão assemelha-se a uma concepção de currículo verticalizado e dicotômico (LOPES; MACEDO, 2011) em que atores que estão externos à escola decidem o que deve ser lecionado e os professores apenas cumprem essa decisão, reduzindo o exercício da profissão docente a uma mera aplicação de conteúdos e metodologias pré-estabelecidas.

Nesse sentido, os professores enxergam as políticas de EA como documentos acabados e imutáveis devendo apenas ser postos em prática. Dessa forma, eles não costumam questionar os pressupostos epistemológicos dos textos políticos como visto nos trabalhos de vários autores (LAYRARGUES, 2002; LOPES VELASCO, 2002, 2013; RODRIGUES E GUIMARÃES, 2010). Um dos poucos questionamentos surgidos foi quanto à maneira como a EA deve ser inserida na escola, se na forma de uma disciplina específica do currículo ou por meio de projetos interdisciplinares e contínuos. É possível interpretar que esta atitude de poucos questionamentos esteja relacionada ao fato dos docentes comumente não discutirem nem deliberarem sobre as políticas de EA por que não são estimulados e não se criam condições para que essas discussões aconteçam dentro da escola.

\section{Compreensão da educação ambiental}

Outra premissa para compreendermos o processo de recontextualização das políticas de EA na construção do currículo escolar foi conhecer os significados que os professores atribuem à educação ambiental. Dessa forma, os professores apresentaram concepções prévias a respeito dos significados de EA que foram agrupadas em quatro categorias. Tais sentidos acionados inicialmente pelos docentes assemelham-se com algumas características definidas nos estudos de Loureiro (2005) para classificar ações de EA.

As categorias EA como forma de educar os indivíduos para preservar o ambiente para as futuras gerações; e EA como conscientização para preservação da flora e fauna são agrupadas por Loureiro (2005) em um bloco denominado como Conservador ou Comportamentalista, do qual podemos citar como características principais uma visão naturalista, descontextualizada e conservacionista da questão ambiental, despolitização das práticas educativas e enfoque em estratégias comportamentalistas. Guiados por esses significados, a maior parte dos professores associou a EA a temas relacionados à 
degradação do meio físico e à questão do lixo. Layrargues (2011) corrobora essa descrição quando classifica como reducionista essas visões da EA, comuns na grande maioria das escolas que implementam programas de EA sobre a temática do lixo, as quais se baseiam unicamente em práticas comportamentalistas de coleta seletiva, deixando de lado uma reflexão crítica e abrangente das práticas do consumismo geradas pelo sistema capitalista e as dimensões econômicas e políticas da temática do lixo.

Outros significados acionados foram EA que sensibiliza o indivíduo à mudança de hábitos e EA como processo de transformação e emancipação do indivíduo na sociedade. Esses últimos são agrupados de acordo com Loureiro (2005) em outro bloco designado pelo autor de Transformador, Crítico ou Emancipatório, e é caracterizado por ações que buscam tornar pública e politizada a complexidade da problemática ambiental, redefinindo o modo como nos relacionamos com o ambiente e as maneiras como exercemos nossa cidadania através da participação ativa na sociedade, como cidadãos críticos acerca da questão ambiental.

A interação oportunizada pelo minicurso também possibilitou a modificação de certas compreensões trazidas pelos professores. No decorrer do estudo, foi possível perceber o movimento de uma visão que se limita ao meio natural e ao problema do lixo, para uma concepção que considera o meio natural, social, político, econômico e cultural. Por meio desse movimento interpretativo, os professores se aproximaram de uma visão crítica de EA, estimulados pela leitura do texto das políticas de EA, pelo acesso a outras fontes de informação como artigos científicos e vídeos acerca do tema escolhido e pelas considerações feitas pelos colegas realizadas durante as discussões por meio da técnica de grupo focal que aconteceram no âmbito do minicurso.

\section{Ações/metodologias da EA}

Os professores relataram que na sua prática docente, quando participavam de ações relacionadas à educação ambiental, desenvolveram diferentes estratégias metodológicas. Sobre as estratégias metodológicas utilizadas pelos professores para executar ações em EA, foram citados projetos interdisciplinares e multidisciplinares, aulas de campo, exposições e feiras de ciências. A maior parte dessas ações foi classificada pelos próprios professores como pontuais e multidisciplinares que "diz respeito à situação em que diversas disciplinas, com base em seu quadro teórico-metodológico, colaboram no estudo ou tratamento de dado fenômeno" (CARVALHO, 2008, p.121). Tal declaração é justificada 
pelos docentes alegando que a escola não comporta ações em um formato interdisciplinar e, além disso, seus agentes não dispõem de formação inicial e continuada em EA.

Debates em torno do Plano de ação de EA

Sobre o processo coletivo de elaboração de uma proposta curricular de educação ambiental, os participantes deliberaram um projeto em meio a reflexões e debates.

Inicialmente, os professores decidiram construir o plano de ação em conjunto com o argumento de que a problemática ambiental é complexa e necessita dos múltiplos olhares e saberes para ser compreendida, escolha feita devido ao fato da perspectiva interdisciplinar ser uma orientação das DCNEA. Contudo, ao que parece, essa dimensão do conhecimento ambiental é apenas uma parte da justificativa. A outra é que o trabalho com projetos se configura como uma via mais flexível para a inserção da EA na escola, por não estar necessariamente condicionado às ementas disciplinares ou às exigências das orientações curriculares mais rígidas.

Foram também estabelecidos critérios sobre as formas de planejamento e de execução do plano de ação segundo a concepção que a produção curricular deve ir de encontro à visão de currículo prescritivo e linear. De início, os professores apresentaram uma compreensão prescritiva de currículo. Contudo, o acordo em escolher uma concepção de currículo como ciclo que integre a participação dos professores nas decisões para a elaboração curricular se deu após as discussões sobre a abordagem do ciclo de políticas.

A inclusão da EA na escola por meio de projetos interdisciplinares orientados por uma visão socioambiental, que tratem de temas locais e globais e estimulem a reflexão crítica do aluno acerca das problemáticas ambientais, foram algumas das orientações das políticas de EA consideradas importantes pelos professores para a produção do currículo de EA nessa escola.

Durante a pesquisa, verificamos que a maioria dos docentes não conhecia os textos da PNEA e das DCNEA. Todavia, mesmo sendo rara a divulgação dessas políticas educacionais de EA em contextos como esse, foi possível perceber que os discursos desses documentos já circulavam na escola entre os professores, que corroboram muitas ideias contidas nesses textos.

Ao analisar os debates em torno da educação ambiental que surgem na produção do currículo, verificamos que questões como interdisciplinaridade e disciplina (POMBO, 1994; GONZALES-GAUDIANO, 2005; CARVALHO, 1998, 2008), transversalidade 
(MACEDO, 1998) e trabalhos por meio de projetos (HERNÁNDEZ, 1998) emergiram como pontos primordiais para o desenvolvimento curricular em EA na escola. Contudo, percebemos que mesmo defendendo que a EA deva ser inserida na forma de projetos e de enxergar o plano de ação como interdisciplinar, alguns professores previram metodologias que seriam aplicadas separadamente por disciplina de acordo com a Tabela 01, revelando a falta da operacionalidade da EA planejada na estrutura por áreas do conhecimento.

Tabela 1. Conteúdos e metodologias propostas pelos professores durante o minicurso.

\begin{tabular}{|c|c|c|}
\hline Disciplina & Conteúdo & Metodologia \\
\hline História & - Revolução Industrial & \\
\hline Ciências & $\begin{array}{l}\text { - Ciclos biogeoquímicos } \\
\text { - Tratamento de esgoto }\end{array}$ & $\begin{array}{l}\text { - Aulas expositivas } \\
\text { - Aulas de campo }\end{array}$ \\
\hline Língua Portuguesa & $\begin{array}{l}\text { - } \begin{array}{l}\text { Leitura, interpretação e } \\
\text { produção de textos }\end{array} \\
\text { - Estudo do vocabulário }\end{array}$ & $\begin{array}{l}\text { - Leitura de textos } \\
\text { - } \quad \text { Produção de textos }\end{array}$ \\
\hline Matemática & $\begin{array}{l}\text { - Razão e proporção } \\
\text { - Gráficos } \\
\text { - } \text { Porcentagem }\end{array}$ & $\begin{array}{l}\text { - Feiras de Ciencias } \\
\text { - Estudo dirigido }\end{array}$ \\
\hline Geografia & - Sistema Capitalista & \\
\hline
\end{tabular}

\section{Fonte: Os Autores (2015)}

Com o decorrer dos debates, houve revisão dos conteúdos e da metodologia do Plano de ação, sendo proposto o tema do consumismo, o qual poderia ser trabalhado por professores de diferentes áreas do conhecimento. A escolha do tema central emergiu em meio a discussões sobre os problemas socioambientais considerados pelos professores como os mais graves enfrentados pela escola. Nesse sentido, os docentes decidiram pela inserção dos conhecimentos pela via da transversalidade combinada com os conteúdos dos componentes já constantes no currículo, em uma interpretação do artigo 16 das DCNEA.

\section{Articulador/articulação}

Outro ponto que merece destaque é que tanto nos encontros do minicurso, quanto nos dias de outras atividades realizadas na escola pesquisada, percebemos que os 
professores são estimulados a desenvolver ações relacionadas à EA se houver uma pessoa, que os professores denominaram de professor articulador, liderando e facilitando as discussões e práticas ambientais desenvolvidas na escola. No presente caso, a proposta do minicurso funcionou como um espaço-tempo de produção curricular de EA e a figura do primeiro autor como de um professor-articulador da EA.

\section{Considerações Finais}

O trabalho realizado indica que, a despeito da EA não integrar os documentos curriculares da escola pesquisada, a proposta da pesquisa e do minicurso contribuíram para que os professores se mobilizassem a trabalhar em grupo, estudar, debater e produzir um plano de ação em EA no seu contexto da prática. Além disso, os professores declararam ter sido essa uma oportunidade de desenvolver novos conhecimentos em relação à produção do currículo e aos temas ambientais e destacaram a importância do curso para sua formação como educadores ambientais, caracterizando a escola como um espaço de formação para professores em serviço.

Esse engajamento foi fundamental para a realização da pesquisa e para uma aproximação ao modo como um grupo de professores recontextualiza políticas curriculares de EA em um contexto da prática. Fez-nos compreender, entre outros aspectos, como o professor se percebe no processo de produção da política curricular e do próprio currículo na escola; ajudou a esclarecer suas concepções prévias de EA e a forma como se juntaram a essas os discursos críticos presentes nas políticas; evidenciou debates locais sobre disciplina, interdisciplinaridade e transversalidade, os quais se reeditam em diversos contextos de produção das políticas educacionais de EA; propiciou, ainda, a definição de um tema para ser trabalhado por meio de projeto interdisciplinar, em tensão constante com a estrutura das disciplinas por áreas do conhecimento.

Para finalizar (sem concluir definitivamente), podemos dizer que a leitura e interpretação dos textos das políticas, proposta pelo minicurso, suscitou debates no grupo, mas não parece ter sido definitiva para o sentido e o desenho que, por fim, ganhou o plano de ação em EA. Mais importante, parece-nos, foi a mediação de um professor articulador, o qual se manteve disponível para preparar os encontros e dialogar com os professores individual e coletivamente. 


\section{Referências}

BALL, Stephen John; MAGUIRE, Meg; BRAUN, Anette. Como as escolas fazem as políticas: atuação em escolas secundárias. Tradução: Janete Bridon. Ponta Grossa: Editora UEPG, 2016. 220p.

BOWE, Richard; BALL, Stephen John; Gold, Anne. Reforming education \& changing school: case studies in policy sociology. London - New York: Routlegde, 1992. 192p.

BRASIL. Lei no 9.795, de 27 de abril de 1999. Dispõe sobre a educação ambiental, institui a Política Nacional de Educação Ambiental e dá outras providências. Brasília, DF: Presidência da República, [1999]. Disponível em: http://www.planalto.gov.br/ccivil_03/leis/19795.htm. Acesso em: 15 jul. 2014.

BRASIL. Resolução n ${ }^{0}$ 2, de 15 de Junho de 2012. Estabelece as Diretrizes Curriculares Nacionais para a Educação Ambiental. Brasília, DF: Presidência da República, [2012]. Disponível em: http://portal.mec.gov.br/dmdocuments/rcp002_12.pdf. Acesso em: $18 \mathrm{dez}$. 2014

CARVALHO, Isabel Cristina de Moura. Em direção ao mundo da vida: interdisciplinaridade e educação ambiental. Brasília: IPE - Instituto de Pesquisas Ecológicas, 1998. 102p. (Cadernos de Educação Ambiental, v.2)

CARVALHO, Isabel Cristina de Moura. Educação Ambiental: a formação do sujeito ecológico. 4. ed. São Paulo: Cortez, 2008. 256p.

FARIAS, Carmen Roselaine de Oliveira. A produção da política curricular nacional para a educação superior diante do acontecimento ambiental: problematizações e desafios. 2008. Tese (Doutorado em Educação). Universidade Federal de São Carlos, São Carlos, 2008.

FARIAS FILHO, Everaldo Nunes. O contexto da prática da Educação Ambiental: interpretações e produção do currículo na escola. 2014. Dissertação (Mestrado em Ensino das Ciências). Universidade Federal Rural de Pernambuco, Recife, 2014.

FOUCAULT, Michel. A ordem do discurso. Tradução: Laura Fraga de Almeida Sampaio. 3. ed. São Paulo: Edições Loyola, 1996. 79p.

GONZÁLEZ-GAUDIANO, Edgar. Interdisciplinaridade e educação ambiental: explorando novos territórios epistêmicos. In: SATO, Michele; CARVALHO, Isabel. Educação ambiental (Org.). Pesquisa e desafios. Porto Alegre: Artmed, 2005. p. 119-133.

GRAY, David. E. Pesquisa no mundo real. Tradução: Roberto Cataldo Costa. 2. ed. Porto Alegre: Penso, 2012. 487p. 
HERNÁNDEZ, Fernando; VENTURA, Montserrat. A organização do currículo por projetos de trabalho: o conhecimento é um caleidoscópio. Tradução: Jussara Haubert Rodrigues. 5. ed. Porto Alegre: Penso, 2017. 198p.

LAYRARGUES, Philippe Pomier. A conjuntura da institucionalização da política nacional de educação ambiental. OLAM: Ciência e Tecnologia, [S.I], v. 2, n.1, p. 1-14, Abr. 2002. 1 CD-ROM.

LAYRARGUES, Philippe Pomier. O cinismo da reciclagem: o significado ideológico da lata de alumínio e suas implicações para a educação ambiental. In: LOUREIRO, Carlos Frederico Bernardo; LAYRARGUES, Philippe Pomier; CASTRO, Ronaldo Souza de. (Org.). Educação ambiental: repensando o espaço da cidadania. 5. Ed. São Paulo: Cortês, 2011. p. 185-225

LEONARD, Annie. A história das coisas: da natureza ao lixo, o que acontece com tudo o que consumimos. 1. ed. Rio de Janeiro: Zahar, 2011. 302p.

LOPES, Alice Casimiro. Políticas curriculares: continuidade ou mudança de rumos? Revista Brasileira de Educação, Rio de Janeiro, n. 26, p. 109-118, maio/ago. 2004.

LOPES, Alice Casimiro. Política de currículo: recontextualização e hibridismo. Revista Currículo sem Fronteiras, [S.I], v. 5, n.2, p. 50-64, jul./dez. 2005.

LOPES, Alice Casimiro. Discursos nas políticas de currículo. Revista Currículo sem Fronteiras, [S.I], v. 6, p. 33-52, jul./dez.2006.

LOPES, Alice Casimiro; MACEDO, Elizabeth. Teorias de Currículo. 1. ed. São Paulo: Cortez, 2011. 279p.

LOPEZ VELASCO, Sirio. Algumas reflexões sobre a PNEA [Política Nacional de Educação Ambiental, Lei No 9.795 de 27/04/1999]. Revista Eletrônica do Mestrado em Educação Ambiental, Rio Grande do Sul, v. 8, p. 12-20, jan./jun. 2002.

LOPEZ VELASCO, Sirio. Explicitação dos conceitos das diretrizes curriculares gerais nacionais para a educação ambiental. Ambiente \& Educação, [S.I], v. 18, n. 1, p. 139152, jul./dez. 2013.

LOUREIRO, Carlos Frederico Bernardo. Complexidade e dialética: contribuições à práxis política e emancipatória em educação ambiental. Educação e Sociedade, Campinas, v. 26, n. 93, p. 131-152, set./dez. 2005.

MACEDO, Elizabeth. Currículo: política, cultura e poder. Currículos sem Fronteiras, [S.I], v. 6, n. 2, p. 98-113, jul./dez. 2006.

MAINARDES, Jefferson. Abordagem do ciclo de políticas: uma contribuição para a análise de políticas educacionais. Educação \& Sociedade, Campinas, v. 27, n. 94, p. 4769, jan./abr. 2006. 
MAINARDES, Jefferson. A Abordagem do Ciclo de Políticas: explorando alguns desafios da sua utilização no campo da política educacional. Jornal de Políticas Educacionais, Curitiba, v. 12, n. 16, p. 1-19, Ago. 2018.

MARCONDES, Maria Inês; FREUND, Cristina; LEITE, Vania Finholdt. Uma nova abordagem ao estudo das políticas educacionais. Revista Práxis Educativa, Ponta Grossa, v. 12, n. 3, p. 1028-1034, set./dez. 2017.

POMBO, Olga; GUIMARÃES, Henrique Martins; LEVY, Tereza. A interdisciplinaridade: reflexão e experiência. 2.ed. Lisboa: Editora, 1994. 102p.

RODRIGUES, Jéssica Nascimento; GUIMARÃES, Mauro. Políticas públicas e educação ambiental na contemporaneidade: uma análise crítica sobre a política nacional de educação ambiental (PNEA). Ambiente \& Educação, [S.I], v. 15, n. 2, p. 13-30, jul./dez. 2010.

TOMAZELLO, Maria Guiomar Carneiro; FERREIRA, Tereza Raquel das Chagas. Educação Ambiental: que critérios adotar para avaliar a adequação pedagógica de seus projetos? Ciência e Educação, Piracicaba, v. 7, n. 2, p. 199-207, jul./dez. 2001. 